\title{
Repetibilidade da produção de cachos de híbridos interespecíficos entre o caiaué e o dendezeiro ${ }^{1}$
}

\author{
Gilson Sánchez CHIA², Ricardo LOPES ${ }^{3}$, Raimundo Nonato Vieira da CUNHA³, Raimundo Nonato Carvalho \\ da ROCHA 3 , Maria Teresa Gomes LOPES ${ }^{4}$
}

RESUMO

A hibridação interespecífica entre o caiaué (Elaeis oleífera (Kunth) Cortés) e o dendezeiro (E. guineensis Jacq.) tem sido explorada com o objetivo de desenvolver cultivares tão produtivas quanto as de dendezeiro, aliada à resistência a pragas e doenças, principalmente o amarelecimento fatal, elevada taxa de ácidos graxos insaturados e redução de porte características do caiaué. Por ser uma cultura perene com longo ciclo de produção, além dos altos custos para manutenção e avaliação dos experimentos de melhoramento genético, é necessário definir o período mínimo de avaliação para que a seleção dos híbridos seja realizada com eficiência e mínimo dispêndio de tempo e recursos. Este estudo teve como objetivo estimar os coeficientes de repetibilidade dos caracteres número de cachos, peso total de cachos e peso médio de cachos de híbridos interespecíficos e definir o número de anos consecutivos de avaliação necessário para seleção eficiente dos melhores cruzamentos e indivíduos. Os coeficientes de repetibilidade foram estimados pelos métodos da análise de variância, componentes principais com base na matriz de covariância (CPCV) e de correlações, e análise estrutural com base na matriz de correlações. O método dos CPCV demonstrou ser o mais adequado para o estudo da repetibilidade da produção de cachos, indicando quatro anos consecutivos de avaliação para selecionar progênies, representadas por dez plantas, com coeficientes de determinação $\left(\mathrm{R}^{2}\right)$ superiores a $85 \%$, e que para seleção individual de plantas são necessários pelo menos seis anos consecutivos de avaliação para atingir $\mathrm{R}^{2}$ superior a $80 \%$.

PALAVRAS-CHAVE: Elaeis guineensis, Elaeis oleifera, hibridação, melhoramento genético.

\section{Repeatability for bunch production in interspecific hybrids between caiaué and african oil palm}

\begin{abstract}
Interspecific hybridization between the caiaué (Elaeis oleifera (Kunth) Cortés) and the african oil palm (E. guineensis Jacq.) has been exploited with the objective of developing varieties as productive as African oil palm and with the pest and disease resistance, reduced height and high levels of insaturated oils characteristic of the caiaué. Perennial crops with long production cycles and high costs for maintenance and evaluation of improvement experiments require definition of minimum evaluation periods for efficient and low cost selection of hybrids. This study estimated the repeatability coefficients of the characters bunch number, total weight of bunches and average bunch weight of interspecific hybrids and determined the number of consecutive years of evaluation required for efficient selection of the best crosses and individuals. The repeatability coefficients were estimated by four methods: analysis of variance, principal components based on the covariance (CPCV) and correlation matrix, and structural analysis based on the correlation matrix. The CPCV method was the most appropriate for the study of the repeatability of bunch production. Four consecutive years of evaluation are required to select progenies, represented by ten plants, with determination coefficients $\left(\mathrm{R}^{2}\right)$ up to $85 \%$, and at least six consecutive years of evaluation are necessary to select individuals, with $\mathrm{R}^{2}$ up to $80 \%$.
\end{abstract}

KEY WORDS: Elaeis guineensis, Elaeis oleifera, hybridization, plant breeding

\footnotetext{
${ }^{1}$ Parte da dissertação de mestrado do primeiro autor apresentada ao Programa de Pós-Graduação em Agricultura no Trópico Úmido/INPA, com apoio financeiro do CNPq - projeto 401120/04-0.

2 Bolsista FAPEAM/Embrapa Amazônia Ocidental, Rod. AM010, Manaus-AM, 69011-970, C.P. 319. gilson.chia@cpaa.embrapa.br.

${ }_{3}^{3}$ Embrapa Amazônia Ocidental, Rod. AM010, Manaus-AM, 69011-970, C.P. 319. ricardo.lopes@cpaa.embrapa.br, raimundo.cunha@cpaa.embrapa.br

${ }^{4}$ FCA-UFAM, Av. Gal. Rodrigo Otávio, 3000, Mini Campus, Manaus-AM, 69077-000. mtglopes@ufam.edu.br.
} 


\section{INTRODUÇÃO}

A dendeicultura é uma atividade de importância agroecológica-industrial com período de exploração comercial de aproximadamente 25 anos. A produção comercial inicia-se três anos após o plantio, mas a capacidade máxima produtiva das plantas ocorre entre seis e sete anos de idade até 17 ou 18 anos de idade, quando as plantas entram em declínio de produção (Barcelos et al., 1987). No Pará, onde se concentra mais de $80 \%$ do plantio no país, plantios adequadamente manejados produzem em média de 4 a 6 t de óleo/ha/ano.

O cutivo do dendezeiro é tecnologicamente bem desenvolvido, sendo a espécie a oleaginosa de maior produtividade e uma das melhores opções para produção de bioenergia nas condições agroecológicas da Amazônia, visto que o plantio é explorado por décadas sem necessidade de preparo do solo, favorecendo a estabilidade de sua estrutura, proporcionando cobertura permanente e evitando o impacto direto das intensas chuvas que provocam erosão e lixiviação; além disso, a cultura não necessita de período de estiagem para colheita ou secagem, como ocorre com os grãos. Possui, ainda, grande capacidade de fixação de carbono, alta eficiência na conversão energética e gera, também, subprodutos com uso energético (cascas, fibras e efluentes de usina de processamento de cachos) (Lopes et al., 2008).

A hibridação interespecífica entre o caiaué (Elaeis oleifera (Kunth) Cortés), espécie americana, e o dendezeiro ( $E$. guineensis Jacq.), espécie africana, tem sido explorada com o objetivo de desenvolver cultivares tão produtivas quanto as de dendezeiro, aliada à resistência a pragas e doenças, principalmente o amarelecimento fatal, alta taxa de óleos insaturados e reduzido crescimento do tronco características do caiaué (Barcelos et al., 2000).

Por ser uma cultura perene com longo ciclo de produção e devido ao alto custo de manutenção e avaliação dos experimentos é necessário definir o período de tempo mínimo para uma avaliação estável de produção dos híbridos interespecíficos dendê x caiaué. A medida da consistência da posição relativa de genótipos durante sucessivas medições é denominada repetibilidade (Turner e Yong, 1969; Lerner, 1977). Em espécies perenes espera-se que o desempenho dos genótipos seja mantido ao longo do tempo; a consistência dessa expectativa é estimada pelo coeficiente de repetibilidade da característica avaliada (Cruz e Regazzi, 1997).

A repetibilidade é função das propriedades genéticas da população, do caráter em estudo e das condições do ambiente nas quais os indivíduos são mantidos (Hansche, 1983; Falconer, 1989; Cedillo, 2003). Pode ser aplicada no estudo de caracteres de plantas perenes que se expressam mais de uma vez no decorrer de seu ciclo, e baseia-se na tomada de mais de uma observação fenotípica no mesmo genótipo (Vencovsky, 1973). Estatisticamente, pode ser definida como a correlação entre as medidas tomadas em um mesmo genótipo, cujas avaliaçôes foram repetidas no tempo (Cruz e Regazzi, 1997), e indica o limite superior que a herdabilidade pode atingir no sentido amplo, constituindo-se num critério para avaliar a eficiência do processo seletivo (Lush, 1964; Cruz e Regazzi, 1997).

Estimativas do coeficiente de repetibilidade tem sido utilizadas no estudo de caracteres associados à produção de várias espécies de palmeiras, como coqueiro comum (Siqueira, 1982), açaizeiro (Oliveira et al., 2001), pupunheira (Farias Neto et al., 2002), coqueiro híbrido (Farias Neto et al., 2003) e dendezeiro (Cedillo, 2003), auxiliando na definição do período adequado de avaliação dos genótipos para maior eficiência dos programas de melhoramento. Em dendezeiro, Cedillo (2003) estimou o coeficiente de repetibilidade da produção de cachos de famílias de meios irmãos de progênies do tipo dura, verificando alta regularidade para produção de cachos, com necessidade de quatro anos de avaliação da produção para seleção acurada das progênies superiores.

Este estudo teve como objetivos estimar o coeficiente de repetibilidade para produção de cachos de híbridos interespecíficos entre o dendezeiro e o caiaué empregando diferentes métodos de estimação, e definir o número de anos de avaliação necessário para seleção acurada dos genótipos.

\section{MATERIAL E MÉTODOS}

O estudo foi desenvolvido na Embrapa Amazônia Ocidental, no Campo Experimental de Rio Urubu, localizado a aproximadamente $140 \mathrm{~km}$ de Manaus, no Distrito Agropecuário da Superintendência da Zona Franca de Manaus (SUFRAMA), às margens do Rio Urubu no município de Rio Preto da Eva, Amazonas. O Clima é do tipo Ami (Classificação de Köppen), quente úmido, temperatura constantemente alta, valores médios de $31,2^{\circ} \mathrm{C}$ e $23,5^{\circ} \mathrm{C}$ para máxima e mínima, respectivamente, e precipitaçóes muito elevadas (em torno de $2.200 \mathrm{~mm} / \mathrm{ano}$ ). O Solo é do tipo Latossolo Amarelo de textura muito argilosa (Guillaumet et al., 2003).

Foram avaliadas dez progênies híbridas, com dez indivíduos cada, obtidas a partir do cruzamento entre plantas de caiaué (genitor feminino) e dendezeiro do tipo pisífera (genitor masculino). As progênies foram plantadas em linha, sem delineamento experimental, no espaçamento $9 \mathrm{~m}$ x $9 \mathrm{~m}$ em triângulo eqüilátero, na densidade de 143 plantas por hectare.

Foram avaliados os caracteres número de cachos (NC), produção total de cachos (PTC) e peso médio dos cachos (PMC), durante sete anos consecutivos, do sétimo ao décimo terceiro ano após o plantio. As colheitas foram realizadas a cada quinze dias durante todos os meses do ano. 
Os coeficientes de repetibilidade foram estimados empregando os métodos da análise de variância (ANOVA), utilizando o modelo com dois fatores de variação (genótipos e anos de avaliação), componentes principais com base na matriz de correlaçôes (CPR) e de covariâncias (CPCV), e análise estrutural com base na matriz de correlações (AER). Foram obtidas também as estimativas do número de avaliaçōes necessárias para predizer o valor real dos genótipos a partir de valores estabelecidos para o coeficiente de determinação $\left(R^{2}\right)$. As estimativas foram obtidas com base na média das progênies (dez plantas) e na média de plantas individuais, uma vez que existe interesse na seleção dos melhores cruzamentos para reprodução comercial e também nas melhores plantas para reprodução por meio de clonagem através de micropropagação. As análises foram realizadas no Aplicativo Computacional em Genética e Estatística - GENES.

\section{RESULTADOS E DISCUSSÃO}

O efeito de progênie foi significativo $(\mathrm{p}<0,01)$ para os três caracteres avaliados, evidenciando a existência de variabilidade genética entre as progênies, portanto, com possibilidade de seleção de cruzamentos superiores. As médias foram 5,98 \pm 2,70 para número de cachos $(\mathrm{NC}), 88,46 \pm 37,38 \mathrm{~kg}$ para peso total de cachos (PTC) e $15,18 \pm 3,86 \mathrm{~kg}$ para peso médio de cachos (PMC).

A estimativa do coeficiente de repetibilidade em nível de média de progênies, com base na avaliação de sete anos de produção para NC, variou de 0,54 (ANOVA) a 0,77 (CPCV); para PTC de 0,48 (ANOVA) a 0,65 (CPCV); e para PMC variou de 0,64 (ANOVA) a 0,80 (CPCV) (Tabela 1). Resende (2002) classifica a estimativa do coeficiente de repetibilidade como alta quando $\geq 0,6$, média quando $<0,6$ e $\geq 0,3$ e baixa quando $<0,3$.

As estimativas obtidas pelo método da ANOVA foram sempre inferiores aos demais métodos e as obtidas pelo $\mathrm{CPCV}$ foram superiores. O método dos componentes principais permite isolar o efeito da alternância, o que não ocorre na análise de variância, ficando esse componente incluído no erro experimental, elevando seu valor e causando viés na estimativa de repetibilidade que será subestimada quando existe efeito da alternância (Abeywardena, 1972; Kendal, 1975; Vasconcellos et al., 1985), fenômeno observado na produção de cachos no dendezeiro e nos híbridos interespecíficos. O método dos componentes principais se mostrou mais eficiente para estimar o coeficiente de repetibilidade da produção de cachos dos híbridos interespecíficos entre o caiaué e o dendezeiro porque isola o efeito da alternância. Trabalhos realizados com outras palmeiras, como pupunheira (Farias Neto et al., 2002), coqueiro híbrido (Farias Neto et al., 2003), e dendezeiro do tipo dura (Cedillo, 2003), também verificaram maior eficiência do método CPCV na obtenção das estimativas do coeficiente de repetibilidade para produção.

As estimativas dos coeficientes de determinação obtidas a partir dos sete anos de avaliação para as três características e pelos quatro métodos foram superiores a $90 \%$, com exceção das obtidas para NC e para PTC pelo método da ANOVA, que foram 89,21 e $85,79 \%$, respectivamente, demonstrando que a seleção das progênies superiores pode ser realizada

Tabela 1 - Estimativas do coeficiente de repetibilidade $(\hat{r})$, coeficiente de determinação $\left(R^{2}\right)$ e número de medições $\left(\eta_{0}\right)$ calculado para os caracteres número de cachos (NC), produção total de cachos (PTC) e peso médio de cacho (PMC) obtidas pelos métodos da análise de variância (ANOVA), Componentes Principais baseados na Matriz de Covariâncias (CPCV) e de Correlações (CPR) e Análise Estrutural baseado na Matriz de Correlações (AER) avaliados durante sete anos consecutivos em 10 progênies de híbridos interespecíficos entre 0 caiaué e dendezeiro tipo Pisífera.

\begin{tabular}{|c|c|c|c|c|c|}
\hline \multirow{2}{*}{ Caráter } & \multirow{2}{*}{ Estimativa } & \multicolumn{4}{|c|}{ Método } \\
\hline & & ANOVA & CPCV & CPR & AER \\
\hline \multirow{5}{*}{ NC } & & 0,54 & 0,77 & 0,65 & 0,63 \\
\hline & $\mathrm{R}^{2}(\%)$ & 89,21 & 95,91 & 92,79 & 92,39 \\
\hline & $\eta$ para $R^{2}=85 \%$ & $5(4,80)$ & $2(1,69)$ & $4(3,08)$ & $4(3,26)$ \\
\hline & $\eta$ para $\mathrm{R}^{2}=90 \%$ & $8(7,62)$ & $3(2,68)$ & $5(4,89)$ & $6(5,18)$ \\
\hline & $\eta$ para $\mathrm{R}^{2}=95 \%$ & $16(16,08)$ & $6(5,67)$ & $11(10,34)$ & $11(10,94)$ \\
\hline \multirow{5}{*}{ PTC } & & 0,46 & 0,65 & 0,58 & 0,56 \\
\hline & $\mathrm{R}^{2}(\%)$ & 85,79 & 92,73 & 90,74 & 90,00 \\
\hline & $\eta$ para $R^{2}=85 \%$ & $7(6,68)$ & $4(3,11)$ & $5(4,05)$ & $5(4,41)$ \\
\hline & $\eta$ para $\mathrm{R}^{2}=90 \%$ & $11(10,43)$ & $5(4,94)$ & $7(6,43)$ & $7(6,99)$ \\
\hline & $\eta$ para $\mathrm{R}^{2}=95 \%$ & $23(22,03)$ & $11(10,42)$ & $14(13,57)$ & $15(14,77)$ \\
\hline \multirow{5}{*}{ PMC } & & 0,64 & 0,80 & 0,74 & 0,74 \\
\hline & $\mathrm{R}^{2}(\%)$ & 92,47 & 96,63 & 95,29 & 95,24 \\
\hline & $\eta$ para $\mathrm{R}^{2}=85 \%$ & $4(3,23)$ & $2(1,38)$ & $2(1,96)$ & $2(1,98)$ \\
\hline & $\eta$ para $\mathrm{R}^{2}=90 \%$ & $6(5,13)$ & $3(2,19)$ & $4(3,12)$ & $4(3,15)$ \\
\hline & $\eta$ para $R^{2}=95 \%$ & $11(10,83)$ & $5(4,64)$ & $7(6,58)$ & $7(6,64)$ \\
\hline
\end{tabular}

(*) Número aproximado (número calculado) 
com alta confiabilidade a partir desse período de avaliação. Contudo, dentro de níveis de precisão aceitáveis na predição do valor dos indivíduos, deve-se buscar redução do período de avaliação para economia de recursos e tempo. Assim, para discriminação das progênies, como nível mínimo de precisão na predição do valor dos indivíduos de $85 \%$, a estimativa do número de anos de avaliação do $\mathrm{NC}$ variou de dois (CPCV) a cinco (ANOVA), para PTC de quatro (CPCV) a sete (ANOVA), e para PMC de dois (CPCV) a quatro (ANOVA). Essas estimativas indicam que com a avaliação da produção por quatro anos consecutivos das progênies híbridas representadas por dez plantas é possível realizar a seleção das progênies com boa acurácia para as características avaliadas.

O efeito de indivíduos também foi significativo $(\mathrm{p}<0,01)$ para os três caracteres avaliados evidenciando a possibilidade de seleção em nível de indivíduos superiores. A estimativa do coeficiente de repetibilidade em nível de indivíduos para NC variou de 0,31 (ANOVA e AER) a 0,41 (CPCV), para PTC de 0,35 (ANOVA) a 0,42 (CPCV) e para PMC de 0,51 (ANOVA) a 0,59 (CPCV) (Tabela 2). Para NC e PTC as estimativas do coeficiente de repetibilidade foram inferiores ou próximas de 0,4 , situação que indica maior dificuldade na identificação dos genótipos superiores e, portanto, necessidade de grande número de mediçôes fenotípicas para boa precisão na seleção dos genótipos. Para atingir valores do coeficiente de determinação $\left(\mathrm{R}^{2}\right)$ superiores a $85 \%$ na avaliação em nível de individuos, o número de anos de avaliação requeridos é de no mínimo nove para NC, oito para PTC e cinco para PMC. Para um nível de precisão superior a $80 \%$, são necessários no mínimo seis anos para NC e PTC e três para PMC.

As estimativas indicam que, na avaliação de híbridos interespecíficos com a finalidade de seleção de indivíduos para clonagem, é necessário um período de avaliação superior ao de avaliação de progênies: pelo menos seis anos consecutivos de avaliação. Considerando que a precisão na seleção não é tão elevada e que antes da multiplicação comercial os genótipos clonados são submetidos a ensaios clonais, deve-se evitar a seleção muito intensa dos genótipos a serem clonados para que maior número de genótipos possam ser avaliados nos ensaios clonais, onde a discriminação dos genótipos superiores pode ser mais precisa com a avaliação de número adequado de réplicas dos genótipos e uso de delineamentos experimentais.

\section{CONCLUSÕES}

Para seleção de progênies híbridas de caiaué com dendezeiro, representadas por pelo menos dez plantas, são necessárias no mínimo quatro anos de avaliação consecutivos da produção de cachos na fase adulta para atingir precisão superior a $85 \%$ na predição do valor das progênies. Para seleção individual de plantas híbridas de caiaué com dendezeiro são necessários pelo menos seis anos de avaliação consecutivos da produção de cachos na fase adulta para atingir precisão

Tabela 2 - Estimativas do coeficiente de repetibilidade $(\hat{r})$, coeficiente de determinação $\left(R^{2}\right)$ e número de medições $\left(\eta_{0}\right)$ calculado para os caracteres número de cachos (NC), produção total de cachos (PTC) e peso médio de cacho (PMC) obtidas pelos métodos da análise de variância (ANOVA), Componentes Principais baseados na Matriz de Covariâncias (CPCV) e de Correlações (CPR) e Análise Estrutural baseado na Matriz de Correlações (AER) avaliados durante sete anos consecutivos em 100 indivíduos de híbridos interespecíficos entre o caiaué e dendezeiro tipo Pisífera.

\begin{tabular}{|c|c|c|c|c|c|}
\hline \multirow{2}{*}{ Caráter } & \multirow{2}{*}{ Estimativa } & \multicolumn{4}{|c|}{ Método } \\
\hline & & ANOVA & CPCV & CPR & AER \\
\hline \multirow{6}{*}{ NC } & & 0,31 & 0,41 & 0,32 & 0,31 \\
\hline & $\mathrm{R}^{2}(\%)$ & 75,58 & 82,79 & 76,40 & 75,12 \\
\hline & $\eta$ para $\mathrm{R}^{2}=80 \%$ & $10(9,05)$ & $6(5,82)$ & $9(8,65)$ & $9(8,98)$ \\
\hline & $\eta$ para $\mathrm{R}^{2}=85 \%$ & $13(12,82)$ & $9(8,26)$ & $13(12,25)$ & $13(12,72)$ \\
\hline & $\eta$ para $\mathrm{R}^{2}=90 \%$ & $21(20,36)$ & $14(13,09)$ & $20(19,46)$ & $21(20,19)$ \\
\hline & $\eta$ para $\mathrm{R}^{2}=95 \%$ & $43(42,98)$ & $28(27,65)$ & $42(41,08)$ & $43(42,64)$ \\
\hline \multirow{6}{*}{ PTC } & & 0,35 & 0,42 & 0,36 & 0,36 \\
\hline & $\mathrm{R}^{2}(\%)$ & 78,97 & 83,29 & 80,06 & 79,48 \\
\hline & $\eta$ para $\mathrm{R}^{2}=80 \%$ & $8(7,46)$ & $6(5,69)$ & $7(6,98)$ & $8(7,23)$ \\
\hline & $\eta$ para $\mathrm{R}^{2}=85 \%$ & $11(10,56)$ & $8(7,96)$ & $10(9,88)$ & $11(10,24)$ \\
\hline & $\eta$ para $\mathrm{R}^{2}=90 \%$ & $17(16,78)$ & $13(12,64)$ & $16(15,69)$ & $17(16,26)$ \\
\hline & $\eta$ para $\mathrm{R}^{2}=95 \%$ & $36(35,42)$ & $27(26,68)$ & $42(41,08)$ & $35(34,33)$ \\
\hline \multirow{6}{*}{ PMC } & & 0,51 & 0,59 & 0,36 & 0,54 \\
\hline & $\mathrm{R}^{2}(\%)$ & 87,88 & 90,84 & 80,06 & 89,23 \\
\hline & $\eta$ para $R^{2}=80 \%$ & $4(3,86)$ & $3(2,83)$ & $7(6,98)$ & $4(3,38)$ \\
\hline & $\eta$ para $\mathrm{R}^{2}=85 \%$ & $6(5,47)$ & $5(4,00)$ & $10(9,88)$ & $5(4,78)$ \\
\hline & $\eta$ para $\mathrm{R}^{2}=90 \%$ & $9(8,69)$ & $7(6,36)$ & $16(15,69)$ & $8(7,59)$ \\
\hline & $\eta$ para $\mathrm{R}^{2}=95 \%$ & $19(18,35)$ & $14(13,42)$ & $34(33,13)$ & $17(16,02)$ \\
\hline
\end{tabular}

(*) Número aproximado (número calculado) 
superior a $80 \%$ na predição do valor dos indivíduos. O método dos Componentes Principais, com base na matriz de covariâncias, demonstrou ser o mais adequado para obter estimativas do coeficiente de repetibilidade da produção de cachos de progênies híbridas entre o caiaué e o dendezeiro.

\section{AGRADECIMENTOS}

Ao Conselho Nacional de Desenvolvimento Científico e Tecnológico $(\mathrm{CNPq})$ pelo financiamento do projeto Processo 401120/04-0, e à Fundação de Amparo à Pesquisa do Estado do Amazonas (FAPEAM) pela bolsa de Mestrado concedida ao primeiro autor.

\section{BIBLIOGRAFIA CITADA}

Abeywardena, V. 1972. An application of component analysis in genetics. Journal of Genetics, 61: 27-51.

Barcelos, E.; Nunes, C.D.M.; Cunha, R.N.V. 2000. Melhoramento genético e produção de sementes comerciais de dendezeiro. In: Viégas, I.J.; Müller, A.A. (Eds). A cultura do dendezeiro na Amazônia brasileira. Embrapa Amazônia Oriental, Belém, PA/ Embrapa Amazônia Ocidental, Manaus, AM. p.145-174.

Barcelos, E.; Pacheco, A.R.; Müller, A.A.; Viégas, I.J.M.; Tinoco, P.B. 1987. Dendê: informaçôes básicas para seu cultivo. EmbrapaDDT, Brasília, DF. 40pp.

Cedillo, D.S.O. 2003. Análises biométricas aplicadas ao melhoramento do dendê (Elaeis guineensis Jacq.). Dissertação de Mestrado, Universidade Federal de Viçosa, Viçosa, MG. 87pp.

Cruz, C.D.; Regazzi, A.J. 1997. Modelos biométricos aplicados ao melhoramento genético. 2 Ed. Universidade Federal de Viçosa, Viçosa, MG. 390pp.

Falconer, D.S. 1989. Introduction to quantitative genetics. Longman, London. 438pp.

Farias Neto, J.T.; Yokomizo, G.; Bianchetti, A. 2002. Coeficientes de repetibilidade genética de caracteres em pupunheira. Revista Brasileira de Fruticultura, 24(3): 731-733.

Farias Neto, J.T.; Lins, P.M.P.; Müller, A.A. 2003. Estimativas dos coeficientes de repetibilidade para produção de frutos de albúmen sólido em coqueiro híbrido. Pesquisa Agropecuária Brasileira, 38(10): 1237-1241.

Guillaumet, J.L.; Rodrigues, M.R.L.; Miranda, I.P.A. 2003. A Estação Experimental do Rio Urubu - Embrapa Amazônia Ocidental. In: Miranda, I.P.A.; Guillaumet, J.L.; Barbosa, E.M.;
Rodrigues, M.R.L.; Silva, M.F.F. (Eds). Ecossistemas florestais em áreas manejadas na Amazônia. Instituto Nacional de Pesquisas da Amazônia, Manaus, AM. p.30-64.

Hansche, P.E. 1983. Response to selection. In: Moore, J.N.; Janick, J. (Eds.). Methods in fruit breeding. Purdue University Press, West Lafayette, Indiana, USA. p.154-171.

Kendall, M.G. 1975. Multivariate analysis. MacMillan, New York, NY. 210pp.

Lerner, I.M. 1977. The genetic basis of selection. John Wiley and Sons, New York, NY. 298pp.

Lopes, R.; Cunha, R.N.V.; Rodrigues, M.R.L.; Teixeira, P.C.; Rocha, R.N.C.; Lima, W.A.A. 2008. Palmaceas. In: Albuquerque, A.C.S.; Silva, A.G. (Eds). Agricultura tropical: quatro décadas de inovaçôes tecnológicas, institucionais e politicas. Embrapa Informação Tecnológica, Brasília, DF. Vol. 1. p. 767-786.

Lush, J.L. 1964. Melhoramento dos animais domésticos. Sedagra, Río de Janeiro, RJ. 570pp.

Oliveira, M.S.P.; Fernandes, G.L.C. 2001. Repetibilidade de caracteres do cacho de açaizeiro nas condições de Belém, PA. Revista Brasileira de Fruticultura, 23(3): 613-616.

Programa Genes - Aplicativo computacional em genética e estatística. www.ufv.br/dbg/genes/genes.htm.

Resende, M.D.V. 2002. Genética biométrica e estatística no melhoramento de plantas perenes. Embrapa Informação Tecnológica, Brasília, DF. 975pp.

Siqueira, E.R. 1982. Coeficiente de repetibilidade da produção de frutos de coqueiro comum. Pesquisa Agropecuária Brasileira, 17(4): 573-574.

Turner, H.N.; Young, S.S.Y. 1969. Quantitative genetics in sheep breeding. Cornell University, Ithaca, NY. 332pp.

Vasconcellos, M.E.C.; Gonçalves, P.S.; Paiva, J.R.; Valois, A.C.C. 1985. Métodos de estimação do coeficiente de repetibilidade no melhoramento da seringueira. Pesquisa Agropecuária Brasileira, 20(4): 433-437.

Venkovsky, R. 1973. Princípios de genética quantitativa. ESALQ, Piracicaba, SP. 97pp.

Recebido em 08/05/2008

Aceito em 28/01/2009 
